\title{
The transcriptional repressor CDP (Cutl1) is essential for epithelial cell differentiation of the lung and the hair follicle
}

\author{
Tammy Ellis, ${ }^{1,4}$ Laure Gambardella, ${ }^{2,4}$ Markus Horcher, ${ }^{1}$ Stefan Tschanz, ${ }^{3}$ Janine Capol, ${ }^{3}$ \\ Paula Bertram, ${ }^{1}$ Wolfram Jochum, ${ }^{1,5}$ Yann Barrandon, ${ }^{2}$ and Meinrad Busslinger ${ }^{1,6}$ \\ ${ }^{1}$ Research Institute of Molecular Pathology, Vienna Biocenter, A-1030 Vienna, Austria; ${ }^{2}$ Department of Biology, École \\ Normale Supérieure, F-75230 Paris, France; ${ }^{3}$ Institute of Anatomy, University of Bern, CH-3000 Bern, Switzerland
}

The mammalian Cutl1 gene codes for the CCAAT displacement protein (CDP), which has been implicated as a transcriptional repressor in diverse processes such as terminal differentiation, cell cycle progression, and the control of nuclear matrix attachment regions. To investigate the in vivo function of Cutl1, we have replaced the C-terminal Cut repeat 3 and homeodomain exons with an in-frame lac $Z$ gene by targeted mutagenesis in the mouse. The CDP-lacZ fusion protein is retained in the cytoplasm and fails to repress gene transcription, indicating that the Cutl1 ${ }^{\text {lacZ }}$ allele corresponds to a null mutation. Cutl1 mutant mice on inbred genetic backgrounds are born at Mendelian frequency, but die shortly after birth because of retarded differentiation of the lung epithelia, which indicates an essential role of CDP in lung maturation. A less pronounced delay in lung development allows Cut11 mutant mice on an outbred background to survive beyond birth. These mice are growth-retarded and develop an abnormal pelage because of disrupted hair follicle morphogenesis. The inner root sheath (IRS) is reduced, and the transcription of Sonic hedgehog and IRS-specific genes is deregulated in Cutl1 mutant hair follicles, consistent with the specific expression of Cutl1 in the progenitors and cell lineages of the IRS. These data implicate CDP in cell-lineage specification during hair follicle morphogenesis, which resembles the role of the related Cut protein in specifying cell fates during Drosophila development.

[Key Words: CCAAT displacement protein; Cux; Cutl1; lung; hair follicle development]

Received February 6, 2001; revised version accepted July 13, 2001.

The CCAAT displacement protein (CDP) was discovered as a sea urchin transcription factor that restricts expression of the sperm $H 2 B$ gene to spermatocytes by binding to the CCAAT promoter element in somatic tissues and thereby preventing access of transcriptional activators to the H2B promoter (Barberis et al. 1987). The human CDP (Superti-Furga et al. 1988) was next shown to act as a repressor of the myelomonocytic $g p 91^{\text {phox }}$ gene (Skalnik et al. 1991) and, upon biochemical purification, was identified as a homolog of the Drosophila homeodomain protein Cut (Neufeld et al. 1992). CDP, which is also known as Cux1 (Cut homeobox-1), and its related Cux2 protein were subsequently isolated from several different vertebrate species (for review, see Nepveu 2001). The

\footnotetext{
${ }^{4}$ These authors contributed equally to this work.

${ }^{5}$ Present address: Institute of Clinical Pathology, University Hospital, Schmelzbergstrasse 12, CH-8091 Zürich, Switzerland.

${ }^{6}$ Corresponding author.

E-MAIL Busslinger@nt.imp.univie.ac.at; FAX 43/1-798-93-70.

Article and publication are at http://www.genesdev.org/cgi/doi/10.1101/ gad.200101.
}

Drosophila Cut protein and its vertebrate homologs share a conserved coiled-coil region at the $\mathrm{N}$ terminus, three internal 60-amino-acid repeats (known as Cut repeats), and a divergent homeodomain located near the $\mathrm{C}$ terminus (Fig. 1B; Blochlinger et al. 1988; Neufeld et al. 1992). The mammalian CDP/Cux1 locus is large and complex, giving rise to at least six different splice products as a result of alternative transcription initiation, splicing, and polyadenylation (Vanden Heuvel et al. 1996; Lievens et al. 1997; Zeng et al. 2000). One of these splice products corresponds to the nuclear protein CASP (CDP alternative splice product), which shares with CDP only the N-terminal coiled-coil sequences (Fig. 1B; Lievens et al. 1997). Here we refer to the mammalian locus as Cutl1 (Cut-like 1) and to its two most prominent protein isoforms as CDP and CASP.

The CDP protein contains four different DNA-binding domains because each of the three Cut repeats is capable of DNA sequence recognition in addition to the homeodomain (for review, see Moon et al. 2000). The presence of multiple DNA-binding modules results in a 
Figure 1. Generation of the Cut $11^{Z}$ allele. (A) Structure of the wild-type and targeted Cut11 loci. The targeting vector is shown together with the genomic structure of exons 21-24 (numbered according to Zeng et al. 2000). Correct targeting was verified by Southern blot analysis of BstXI-digested DNA with the indicated probe. The lengths of the BstXI fragments are shown in kilobases. (Ba) BamHI; (Bs) BsaI; (Bx) BstXI; (Sp) SphI; (St) StyI; (pA) polyadenylation site; (CR3) Cut repeat 3; (HD) homeodomain; $(\mathrm{RD})$ repression domain; (neo) neomycin; (tk) thymidine kinase. (B) Schematic diagram of the different proteins enognized by the N[-861] and C3HD antibodies are indicated. (CC) Coiled-coil region. (C) Southern blot analysis of BstXI-digested DNA from Cut $11^{+/ Z}$ offspring. (D) Western blot analysis. Low-salt protein extracts of primary embryo fibroblasts were analyzed by immunoblotting with the nuclear CDP protein was only partially extracted at $120 \mathrm{mM} \mathrm{KCl}$ in contrast to the cytoplasmic CDP-lacZ protein. (X) Crossreacting protein. $(E)$ Subcellular localization of CDP proteins. Cut $11^{+/ Z}$ fibroblasts were simultaneously stained with antiCDP (C3HD) and anti- $\beta$-galactosidase antibodies. $(F)$ Absence of transcriptional repression by CDP-lacZ. The CDP and/or CDP-lacZ expression plasmids (1-20 ng) were transiently transfected into NIH 3T3 cells together with the SP1- $\gamma$-TATA-luciferase gene (100 ng, shown below) and $(10 \mathrm{ng})$. After $48 \mathrm{~h}$, the activity of the firefly luciferase was measured and standardized relative to that of the control Renilla luciferase. Average values of six experiments are shown relative to the activity measured with the empty expression vector pRK5 (100\%, left bar). The CDP and CDP-lacZ proteins were expressed at similar levels (data not shown). coded by the Cut11 loci. The epitopes rec$\mathrm{N}[-861]$ and C3HD antibodies. The the Renilla luciferase construct pRL-SV40
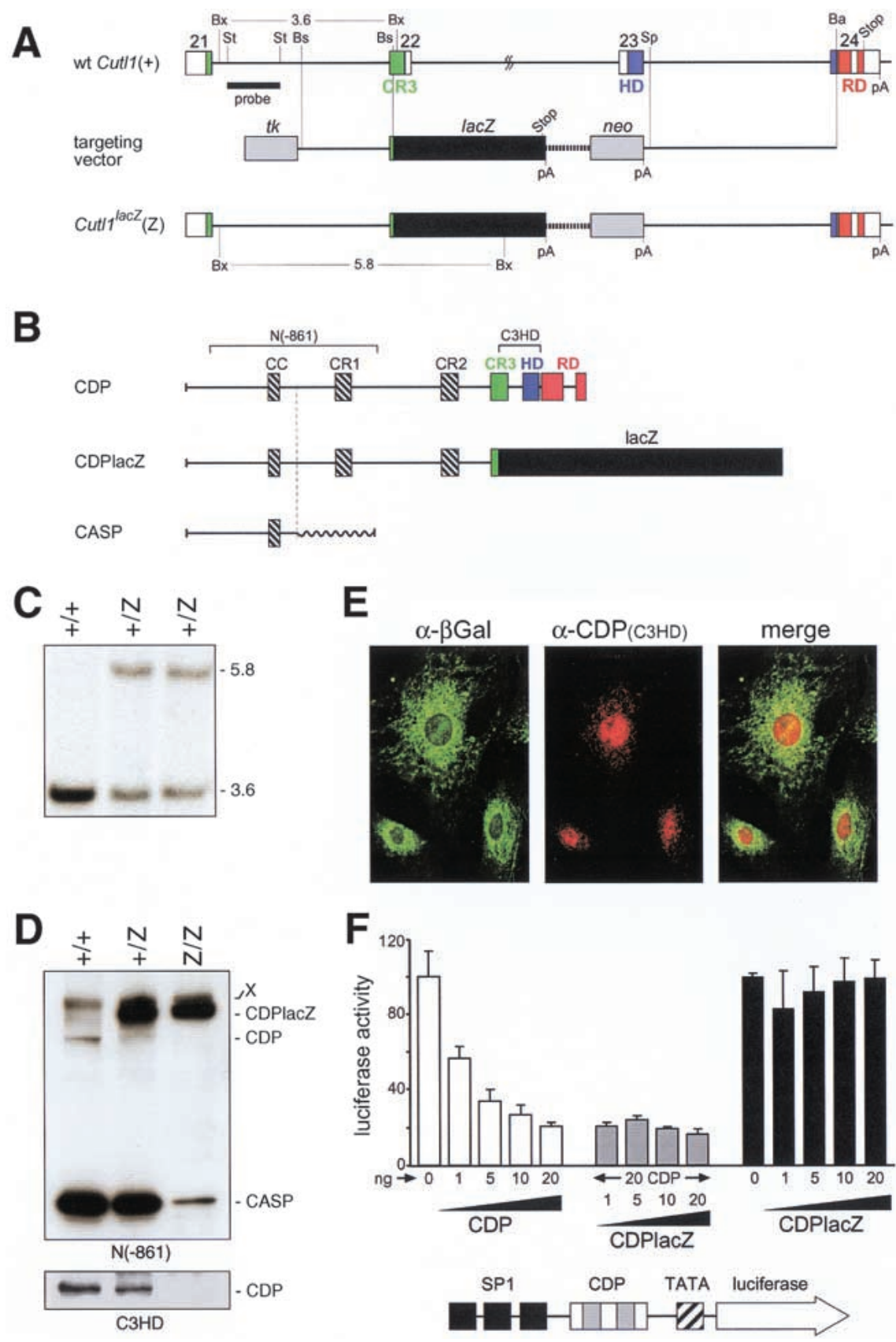

Protein-DNA binding studies and functional promoter highly flexible mode of sequence recognition, thus providing an explanation for the ability of CDP to bind to a large spectrum of different DNA sequences (Moon et al. 2000). Once bound to DNA, CDP represses target gene transcription by two distinct mechanisms. In one mechanism, it interferes with the binding of transcriptional activators by competing for binding-site occupancy (Barberis et al. 1987; Skalnik et al. 1991; Mailly et al. 1996). This CCAAT-displacement activity is mediated by the Cut repeats 1 and 2 (Moon et al. 2000). Alternatively, the CDP protein can actively repress gene transcription through its C-terminal sequences, which bind to and thus recruit histone deacetylases (HDAC) to target gene promoters (Mailly et al. 1996; Li et al. 1999). analyses have implicated the CDP protein in the regulation of a large variety of cellular and viral genes, including the $g p 91^{\text {phox }}, \mathrm{c}-m y c$, c-mos, N-cam, CFTR, p21 WAF1/CIP1, lactoferrin, tyrosine hydroxylase, thymidine kinase, and histone genes (for review, see Nepveu 2001). Although these genes have not been genetically verified to be endogenous targets of CDP, their functions have led to several hypotheses concerning the in vivo role of CDP. The inverse correlation between the expression of the CDP repressor and its target gene $g p 91^{\text {phox }}$ during myeloid differentiation has led to the hypothesis that CDP functions in lineage-committed precursor cells to repress genes, which are activated only during the CDP-negative 
phase of terminal differentiation (Skalnik et al. 1991; Lievens et al. 1995; Wang et al. 1999). An alternative, but not mutually exclusive function implicates CDP in the control of cell-cycle progression based on the following evidence. First, the DNA-binding activity of CDP was shown to oscillate during the cell cycle, reaching maximal levels during late $G_{1}$ and the $S$ phase (Coqueret et al. 1998). Second, CDP was identified as the DNA-binding component of the cell-cycle-regulated, Rb-containing transcription factor complex HiNF-D (van Wijnen et al. 1996). Third, several of the putative CDP target genes (see above) are regulated in a cell-cycle-dependent manner. Finally, CDP has also been proposed to function as an architectural protein, as it binds to and negatively regulates nuclear matrix attachment regions in the $C D 8 \alpha$, T cell receptor $\beta(T C R \beta)$, and immunoglobulin heavy-chain $(\operatorname{IgH})$ loci (Banan et al. 1997; Chattopadhyay et al. 1998; Wang et al. 1999).

Genetic studies revealed different functions of the cut gene during Drosophila development. Loss- and gain-offunction analysis showed that Cut is not only necessary but also sufficient for specifying the identity of external sensory organs during peripheral nervous system development (Blochlinger et al. 1988, 1991). However, Cut also fulfills non-cell-autonomous functions during the formation of the egg chamber and wing margin, where it is involved in the control of intercellular communication (Jackson and Blochlinger 1997; Micchelli et al. 1997). Interestingly, ectopic expression of the mammalian CDP protein in Drosophila was able to rescue the cut wing mutant phenotype, indicating that the function of Cut and CDP proteins has been conserved in evolution (Ludlow et al. 1996).

Here we have analyzed the in vivo function of the mouse Cutl1 gene by targeted replacement of the Cut repeat 3 and homeodomain exons with an in-frame lacZ gene, which resulted in a transcriptionally inactive fusion protein. Homozygous mutant mice on inbred genetic backgrounds died at birth from respiratory failure, which was caused by retarded differentiation of the lung epithelia. This delay in lung development was less pronounced in Cutl1 mutant mice on an outbred background, which survived but were growth-retarded. These mice had a sparse pelage of abnormal hair caused by severe impairment of hair follicle development. The cell layers of the inner root sheath (IRS) were reduced in Cut11 mutant hair follicles, consistent with the finding that Cutl1 is selectively expressed in the progenitors and cell lineages of the IRS. Moreover, the expression of Sonic hedgehog and IRS-specific genes was deregulated in Cut11 mutant hair follicles. These data indicate a role of CDP in cell lineage specification of the hair follicle in analogy with the selector function of Drosophila Cut in the peripheral nervous system.

\section{Results}

\section{Targeted mutation of the Cutl1 gene}

The mammalian Cutl1 locus is highly complex, as it spans at least $340 \mathrm{~kb}$ of genomic DNA, codes for $33 \mathrm{ex}-$ ons, is transcribed from different promoters, and gives rise to several alternative splice products (Vanden Heuvel et al. 1996; Lievens et al. 1997; Tufarelli et al. 1998; Zeng et al. 2000). However, all CDP isoforms end with the same C-terminal sequences containing the DNAbinding regions of the Cut repeat 3 and homeodomain as well as two repression domains. Because these functional domains are essential for the DNA-binding and repression activities of CDP (Nepveu 2001), we chose to inactivate the Cutl1 gene by targeting these C-terminal sequences (Fig. 1A). Moreover, as the developmental expression pattern of the Cutl1 gene is only partially known, we inserted a lacZ $(Z)$ gene in-frame into Cutl1 exon 22 to be able to follow the expression of the targeted allele by $\beta$-galactosidase staining (Fig. 1A). Correctly targeted ES cells were injected into blastocysts to generate heterozygous Cut $11^{+/ Z}$ mice (Fig. 1C), which were indistinguishable from their wild-type littermates with regard to viability, growth, behavior, and fertility.

To characterize the Cutl1 ${ }^{z}$ mutation molecularly, we cultured primary fibroblasts from wild-type and Cutl1 mutant embryos and subsequently analyzed protein extracts of these cells by Western blotting (Fig. 1D). An antibody recognizing $\mathrm{N}$-terminal CDP sequences (N[-861]) detected both the full-length CDP protein (180 $\mathrm{kD})$ and the alternative splice product CASP $(80 \mathrm{kD})$ in wild-type fibroblasts. In contrast, homozygous Cut $11^{Z / Z}$ fibroblasts expressed the larger CDP-lacZ fusion protein (250 kD) instead of full-length CDP. Expression of the CASP protein was maintained in these fibroblasts, although at a sixfold lower level (Fig. 1D), which could reflect a decrease in alternative splicing of the CASP transcript. The presence of two additional polyadenylation sites between exons 22 and 24 of the targeted Cut11 allele (Fig. 1A) may, indeed, increase the efficiency of polyadenylation in this region and thus interfere with alternative splicing of the primary transcript from exon 14 to the downstream exons 25-33 coding for the unique C-terminal sequences of CASP (Fig. 1B; Lievens et al. 1997; Zeng et al. 2000).

We investigated the subcellular localization of the CDP and CDP-lacZ proteins by immunostaining of heterozygous Cutl1 ${ }^{+/ Z}$ fibroblasts. An antibody (C3HD) that recognizes the Cut repeat 3 and homeodomain sequences deleted in the Cutl1 ${ }^{Z}$ allele (Fig. 1B) localized the wild-type CDP protein predominantly in the nucleus of $\mathrm{Cutl1}^{+/ Z}$ fibroblasts (Fig. 1E). Surprisingly, however, the CDP-lacZ protein was excluded from the nucleus, as it was detected with an anti- $\beta \mathrm{Gal}$ antibody in the cytoplasm of the same fibroblasts. Hence, the CDP-lacZ protein is sequestered away from the nucleus, where CDP normally functions to regulate gene transcription.

The transcriptional activity of the wild-type CDP and CDP-lacZ fusion proteins was next compared in transiently transfected NIH 3T3 cells. As shown in Figure $1 \mathrm{~F}$, increasing amounts of exogenous CDP protein efficiently repressed the activity of a cotransfected SP1- $\gamma-$ TATA-luciferase gene (Lievens et al. 1995), in marked contrast to the CDP-lacZ protein. Moreover, coexpression of CDP-lacZ failed to interfere with the repression 
function of CDP, thus excluding a dominant-negative function of the fusion protein. In summary, the lack of repression activity and the cytoplasmic location of the CDP-lacZ protein strongly argue that the targeted mutation abrogates the transcriptional function of CDP and therefore corresponds to a null allele.

\section{Postnatal lethality and growth retardation of Cutll mutant mice}

Intercrosses of heterozygous mutant mice showed that Cut $11^{Z / Z}$ mice are born at the expected Mendelian frequency, indicating that the Cut $11^{Z}$ mutation does not interfere with embryonic development. However, the Cut $11^{Z / Z}$ mice died shortly after birth from respiratory failure. This early postnatal lethality was observed with Cut $11^{Z / Z}$ mice that were bred on the $\mathrm{C} 3 \mathrm{H} / \mathrm{He}$ or $\mathrm{C} 57 \mathrm{BL} /$ $6 \times 129 / \mathrm{Sv}$ strain background. A few Cutl1 ${ }^{\mathrm{Z} / Z}$ mice $(\sim 1 \%)$ on the latter genetic background survived beyond birth, but then were severely growth-retarded and had only a sparse pelage of abnormal hair (Fig. $2 \mathrm{~A}, \mathrm{~B}$ ). In marked contrast, the majority of Cut $11^{Z / Z}$ mice survived on the outbred OF1 background, but were still growthretarded (Fig. 2C). Because abnormal function of the pituitary or thyroid glands could explain the observed growth retardation, we measured the levels of growth hormone (GH) and thyroid-stimulating hormone (TSH) in the blood of 2-week-old Cut $11^{Z / Z}$ mice. Growth hormone was present in the sera of mutant $(n=8)$ and wildtype $(n=6)$ mice at 5.3 and $7.0 \mathrm{ng} / \mathrm{mL}$ and TSH at 138 and $118 \mathrm{ng} / \mathrm{mL}$, respectively. Therefore, the normal synthesis of these hormones indicates that the observed growth retardation of Cut $11^{\mathrm{Z} / \mathrm{Z}}$ mice is not caused by dysfunction of the thyroid or pituitary glands, although Cut11 is expressed during the development of these organs (see below).

\section{Cutll expression during development}

We next analyzed the developmental expression pattern of Cut11 by $\beta$-galactosidase staining of mutant embryos. Cut11 expression was detected in most tissues at embryonic day 8.5 (E8.5) and, starting with E12.5, became gradually restricted to a subset of organs (data not shown). The Cutl1 gene was specifically expressed in the epithelial compartment of the developing whisker, tooth, choroid plexus, Rathke's pouch (pituitary), thyroid, salivary gland, pancreas, kidney, and lung (Figs. 2D$\mathrm{H}, 3 \mathrm{~A}, \mathrm{~B}$; data not shown). In addition, Cut11 was also expressed in striated and smooth muscles of various organs (Fig. 2G,I) and in hypertrophic chondrocytes of developing bones (data not shown).

The Cut11 gene is most highly expressed in the testis among all tissues of adult males (Vanden Heuvel et al. 1996). Consistent with this finding, $\beta$-galactosidase staining was detected in the postmeiotic round and elongating spermatids, but neither in spermatocytes, elongated spermatids, nor mature sperm in the testes of het-
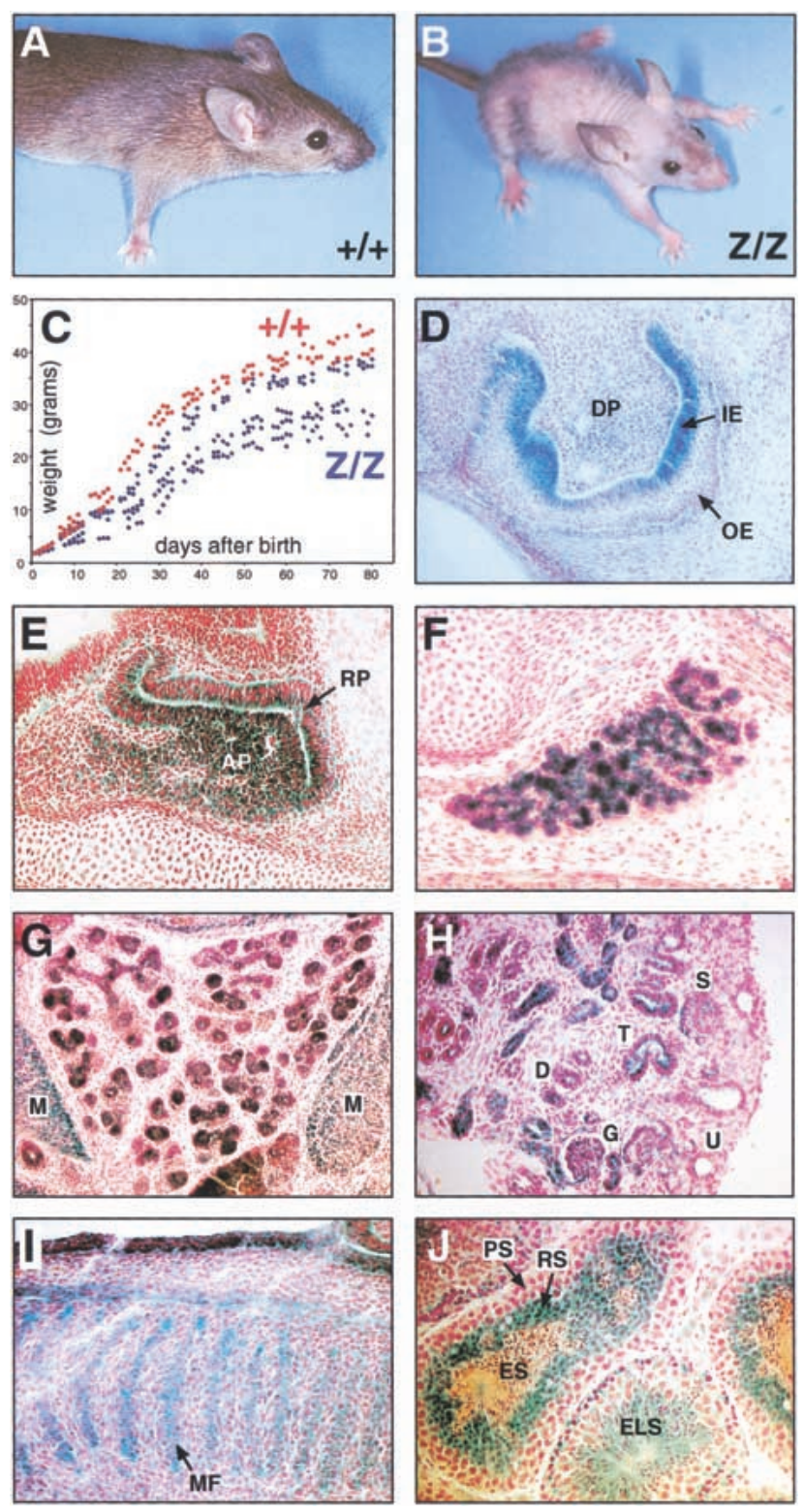

Figure 2. Growth retardation and expression analysis of Cutl1 mutant mice. $(A, B)$ View of a wild-type mouse $(A)$ and its surviving Cut $11^{Z / Z}$ littermate $(B)$ (on the C57BL/6 $\times 129 /$ Sv background) at postnatal day 37. (C) Delayed growth of Cut11 ${ }^{Z / Z}$ mice maintained on the OF1 background. The weight of wildtype $(n=3)$ and $\operatorname{Cut}_{11}{ }^{Z / Z}(n=6)$ mice was measured at regular intervals after birth. $(D-J)$ Cut11 expression in the developing incisor tooth $(D)$, pituitary $(E)$, thyroid $(F)$, salivary gland $(G)$, kidney $(H)$, tongue muscle $(I)$, and testis $(J)$. X-Gal staining was performed on cryosections of Cut11 ${ }^{Z / Z}$ fetuses at day $14.5(D, E$, I) or day $16.5(F-H)$ and of the testis of a 3-month-old Cut $11^{+/ Z}$ mouse (J). (AP) Anterior pituitary; (D) collecting duct; (DP) dental papilla; (ELS) elongating spermatid; (ES) elongated spermatid; (G) glomerulus; (IE) inner enamel epithelium; (M) muscle; (MF) muscle fiber; (OE) outer enamel epithelium; (PS) pachytene spermatocyte; (RP) Rathke's pouch; (RS) round spermatid; (S) S-shaped body; $(\mathrm{T})$ tubule; $(\mathrm{U})$ ureteric tip.

erozygous males (Fig. 2J). Surprisingly, however, matings of Cut $11^{Z / Z}$ OF1 males with wild-type females resulted 

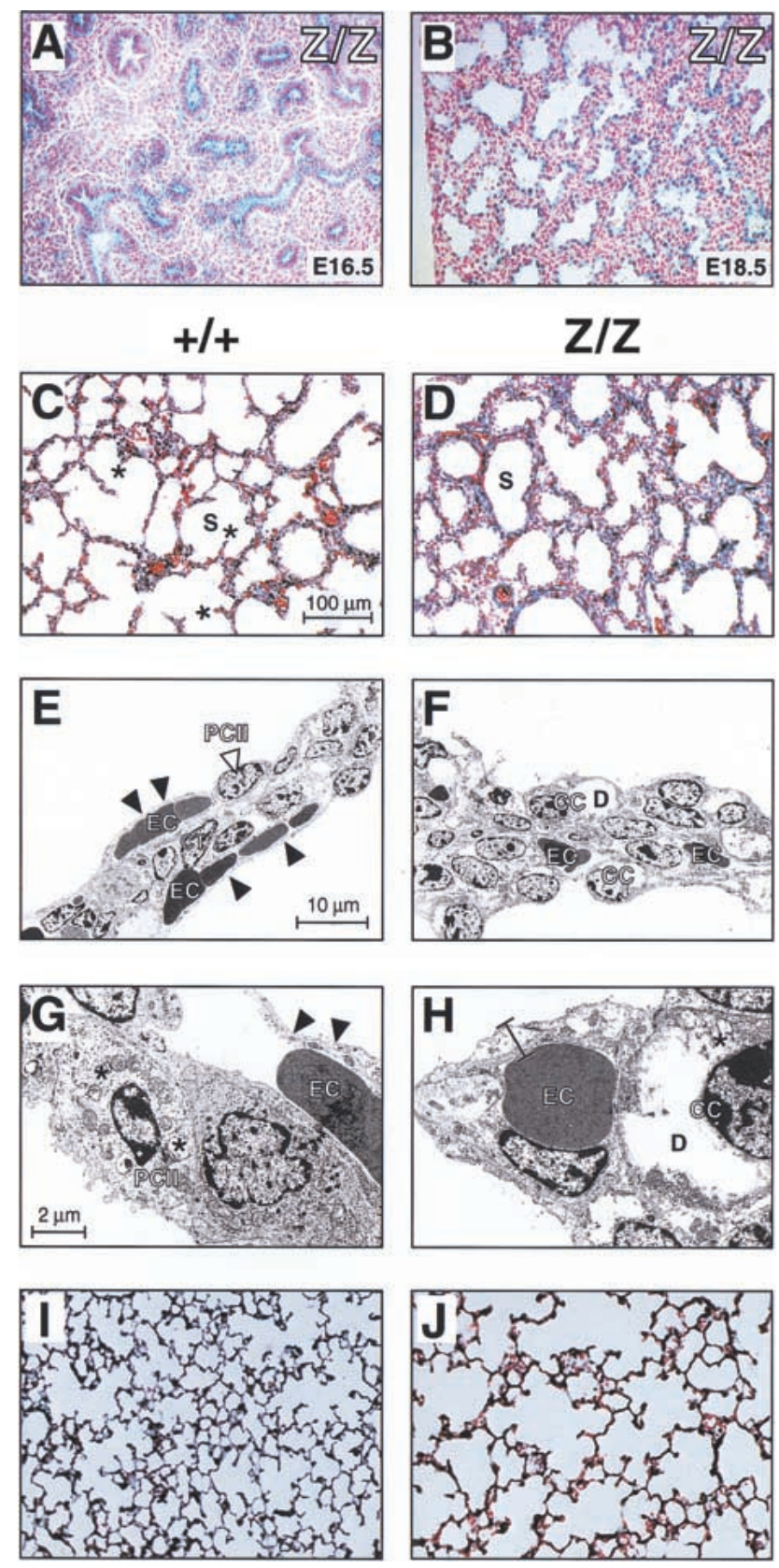

Figure 3. Developmental abnormalities of the Cut11 mutant lung. $(A, B) \beta$-Galactosidase staining of lung cryosections from

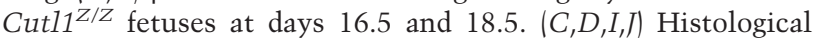
analysis of inflated lungs at birth $(C, D)$ and postnatal day $21(I, J)$. Asterisks denote the outgrowth of secondary septa within the saccules (S). $(E-H)$ Transmission electron micrographs of lung septa at birth. The septa of the Cut $11^{Z / Z}$ mouse $(F, H)$ are composed of cuboidal epithelial cells (CC), which contain large deposits (D) of loose material (probably glycogen), as shown at high magnification $(H)$. In contrast, the wild-type lung $(E, G)$ consists of type I and II pneumocytes (PC) and two layers of erythrocyte (EC)-containing capillaries that are separated by connective tissue (CT). The type II pneumocytes contain many lamellar bodies (asterisks). Arrowheads point to the thin bloodair barrier, which is composed of type I pneumocytes and endothelial cells of the capillary. All analyses were performed with mice on the C57BL/6 $\times 129 /$ Sv background. in litters of normal size, demonstrating that the Cut $11^{Z}$ mutation does not impair male fertility.

\section{Retardation of lung development in Cutl1 mutant mice}

Histological examination of newborn $\mathrm{Cutl1}^{\mathrm{Z} / Z}$ mice revealed morphological abnormalities in the lung and skin. During lung development, Cut11 expression was first observed in the columnar epithelium of the bronchioles at E12.5, was increased during the canalicular and saccular stages of lung morphogenesis (E16.5-E18.5), and then became undetectable in the mature lung at 3 wk of age (Fig. $3 \mathrm{~A}, \mathrm{~B}$; data not shown). Consistent with this expression pattern, Cut $11^{Z / Z}$ mice on inbred backgrounds became cyanotic shortly after birth despite normal respiratory muscle contractions and died within 2-6 h from lung failure. This Cutl1 mutant phenotype resembles the respiratory distress syndrome of human infants, wherein inadequate surfactant levels do not allow proper inflation of the immature lung (Burri 1999). In contrast to the human condition, however, Cut $11^{Z / Z}$ pups could not be rescued by intraperitoneal injection of dexamethasone into pregnant females at days $16.5-18.5$ of gestation. Moreover, quantitative RT-PCR analyses revealed that the surfactant genes $S P-A, S P-B$, and $S P-C$ were normally transcribed in Cutl1 ${ }^{Z / Z}$ lungs at birth (data not shown).

Histological and electron microscopic analyses revealed a lower complexity of the lung parenchyma in newborn Cut11 ${ }^{Z / Z}$ mice compared with wild-type littermates (Fig. 3C,D). At birth, wild-type lungs are at the late saccular stage, which is characterized by septa containing two layers of capillaries on either side of a thin axial sheath of interstitial cells (Fig. 3C,E). Flat type I pneumocytes and capillary endothelial cells (Fig. 3E,G, arrowheads) constitute a thin blood-air barrier facilitating an efficient gas exchange, and the septa contain type II pneumocytes with their characteristic lamellar bodies, which are involved in the storage and exocytosis of surfactant proteins (Fig. 3G). The growth of secondary septa (Fig. 3C, asterisks) has started to subdivide the lumen of the saccules, thus initiating the process of alveolization. In marked contrast, the septa of newborn Cut $11^{Z / Z}$ lungs were still thick, with a broad interstitial cell layer and a loose arrangement of capillaries (Fig. 3D,F). The septal walls were very smooth and formed round saccules lacking any outgrowth of secondary septa (Fig. 3D). Instead of type I and II pneumocytes, the Cutl1 ${ }^{Z / Z}$ septa contained many cuboidal cells, which are considered to be pneumocyte precursors (Fig. 3F,H). In summary, the lungs of Cut11 ${ }^{Z / Z}$ newborns displayed morphological features normally seen only at the beginning of the saccular stage, indicating that the lack of Cutl1 function leads to a maturation delay of $2 \mathrm{~d}$. The observed retardation results in the absence of a mature blood-air barrier at birth and is most likely responsible for the respiratory failure of newborn Cutl1 ${ }^{Z / Z}$ pups on inbred strain backgrounds.

Analysis of adult Cut $11^{Z / Z}$ survivors revealed that the lungs of these mice contained fully differentiated type I and type II pneumocytes, a well-developed blood-air barrier, and a mature microvasculature. However, the air 
spaces were markedly dilated, and the lungs displayed a decreased complexity of the alveolar network as a consequence of delayed initiation and/or incomplete execution of the alveolar differentiation program (Fig. 3J). Therefore, we conclude that Cutl1 is essential for proper maturation of the lung.

\section{Defective hair formation in Cutl1 mutant mice}

The absence of a normal hair coat was a consistent and background-independent phenotype of all surviving Cut11 ${ }^{Z / Z}$ mice (Fig. 2B). A defect in hair follicle development was already apparent at birth, as Cut $11^{Z / Z}$ pups were born with only a few stunted and curly whiskers (Fig. 4B). These mice initially developed a rudimentary hair coat, but after 1 wk started to lose most of their pelage hair (Fig. 2B). This phenotype was also recapitulated in grafts of newborn Cut11 ${ }^{Z / Z}$ skin that were transplanted onto athymic $(n u / n u)$ mice. The Cut $11^{Z / Z}$ skin grafts developed only sparse, short, and disorganized hair (Fig. 4D) in contrast to the dense fur generated by wildtype skin grafts (Fig. 4C). The hair coat of a wild-type mouse is composed of four different hair types known as guard, awl, auchene, and zig-zag hair (Philpott and Paus 1998). These hair types could not be identified in the $\mathrm{Cutl1}^{Z / Z}$ skin, which instead gave rise to all major hair abnormalities found in different human skin diseases (Whiting 1994). The same Cutl1 ${ }^{Z / Z}$ pelage contained twisted, bifurcated, circle, and corkscrew hair as well as hair with nodules or longitudinal grooving (Fig. 4E-J). Furthermore, electron microscopy showed that scales were absent on the Cutl1 mutant hair, which may reflect abnormal development of the cuticle cell layers in the hair follicle (Fig. 4L).

The hair follicles initially developed normally and are present in correct numbers in the dorsal skin of 18.5-dayold Cut $11^{Z / Z}$ fetuses (Fig. 5A,B). In contrast, their morphogenesis was severely disrupted in 3-week-old Cut11 $^{Z / Z}$ mice (Fig. 5C,D). Most hair follicles were extremely misoriented, often appeared cystic or even sclerotic, and contained more than one degenerated hair shaft (Fig. 5D,E). The viable hair follicles expressed the Cutl1 ${ }^{\text {lacz }}$ gene in all cell layers except in the outer root sheath and dermal papilla (Fig. 5E,F). Importantly, the hair follicles in the Cut $11^{Z / Z}$ skin grafts were equally disorganized (data not shown), demonstrating that the disruption of hair development is caused by a skin-autonomous defect.

\section{Abnormal differentiation of the inner root sheath in Cutl1 mutant hair follicles}

We next studied the expression of the Cutl1 gene in the whisker follicle, which, as the largest of all hair follicles, provides the highest cellular resolution. The dermal papilla of the whisker follicle is surrounded by an epithelial core that is composed of several concentric cell layers comprising the outer root sheath (ORS), inner root sheath (IRS), and hair shaft (Fig. 6D). Each layer consists
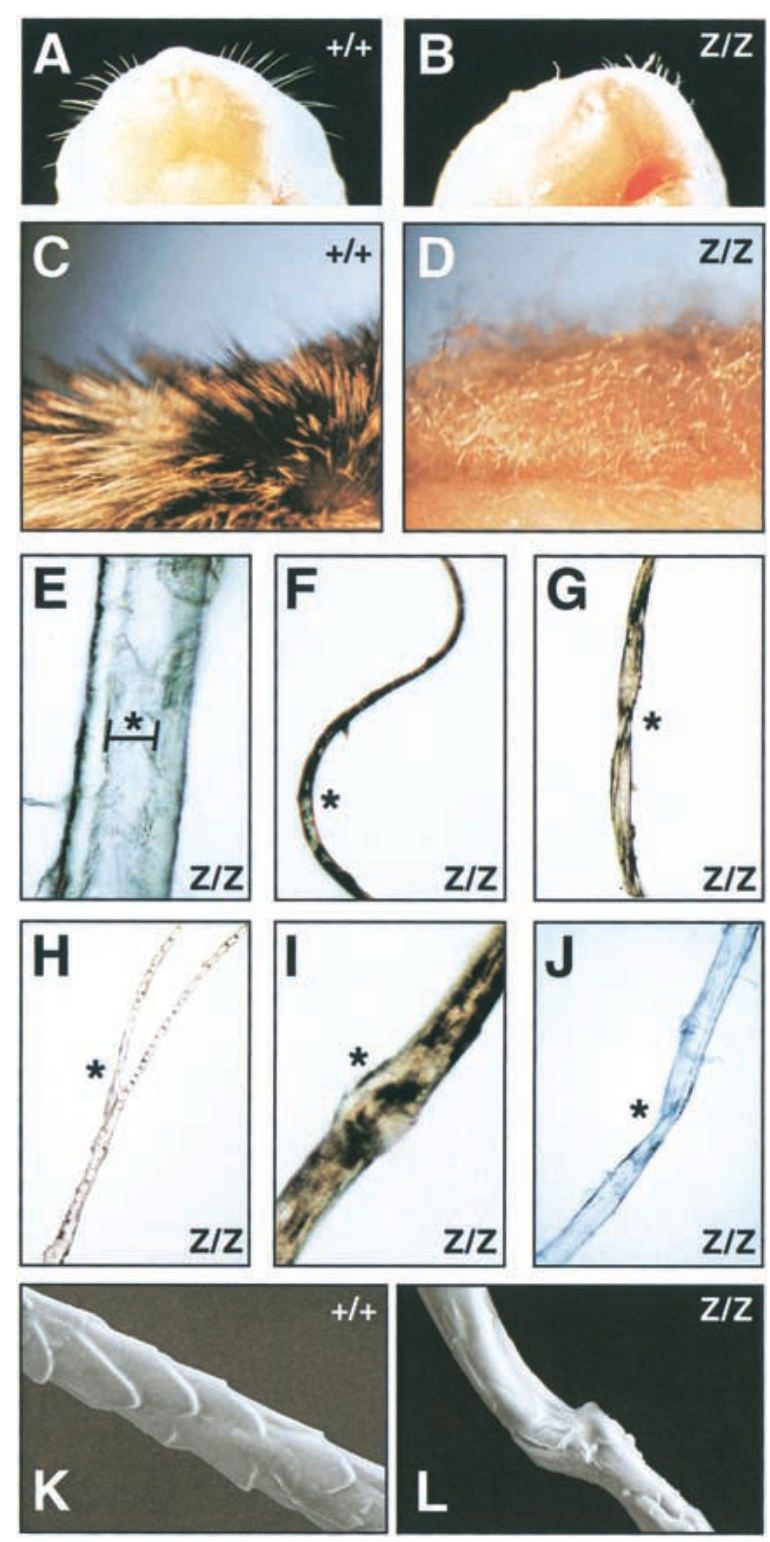

Figure 4. Aberrant hair formation in Cut11 mutant mice. $(A, B)$ View of the snout of newborn wild-type and Cut $11^{Z / Z}$ mice. $(C, D)$ Close-up view of the fur of a wild-type $(C)$ and $C u t 11^{Z / Z}$ $(D)$ skin graft at 6 wk after transplantation onto an athymic $(\mathrm{nu} / \mathrm{nu})$ mouse. (E-J) Multiple abnormalities of pelage hair taken from the same Cut $11^{Z / Z}$ skin graft. Hair with longitudinal grooving (bracket in $E)$, circle hair $(F)$, pili torti $(G)$, bifurcated hair $(H)$, trichorrhexis nodosa $(I)$, and corkscrew hair $(J)$. Asterisks indicate the different hair abnormalities. $(K, L)$ Scanning electron micrograph of pelage hair. Scales are absent on the surface of the Cutl1 mutant hair $(L)$ in contrast to wild-type hair $(K)$.

of different cell lineages, which are derived from the same multipotent stem cell located in the bulge of the hair follicle. This stem cell migrates from the bulge through the basal layer of the ORS to the matrix region of the hair bulb, where it becomes committed to one of the distinct cell lineages of the hair follicle (Fig. 6D; Tay- 

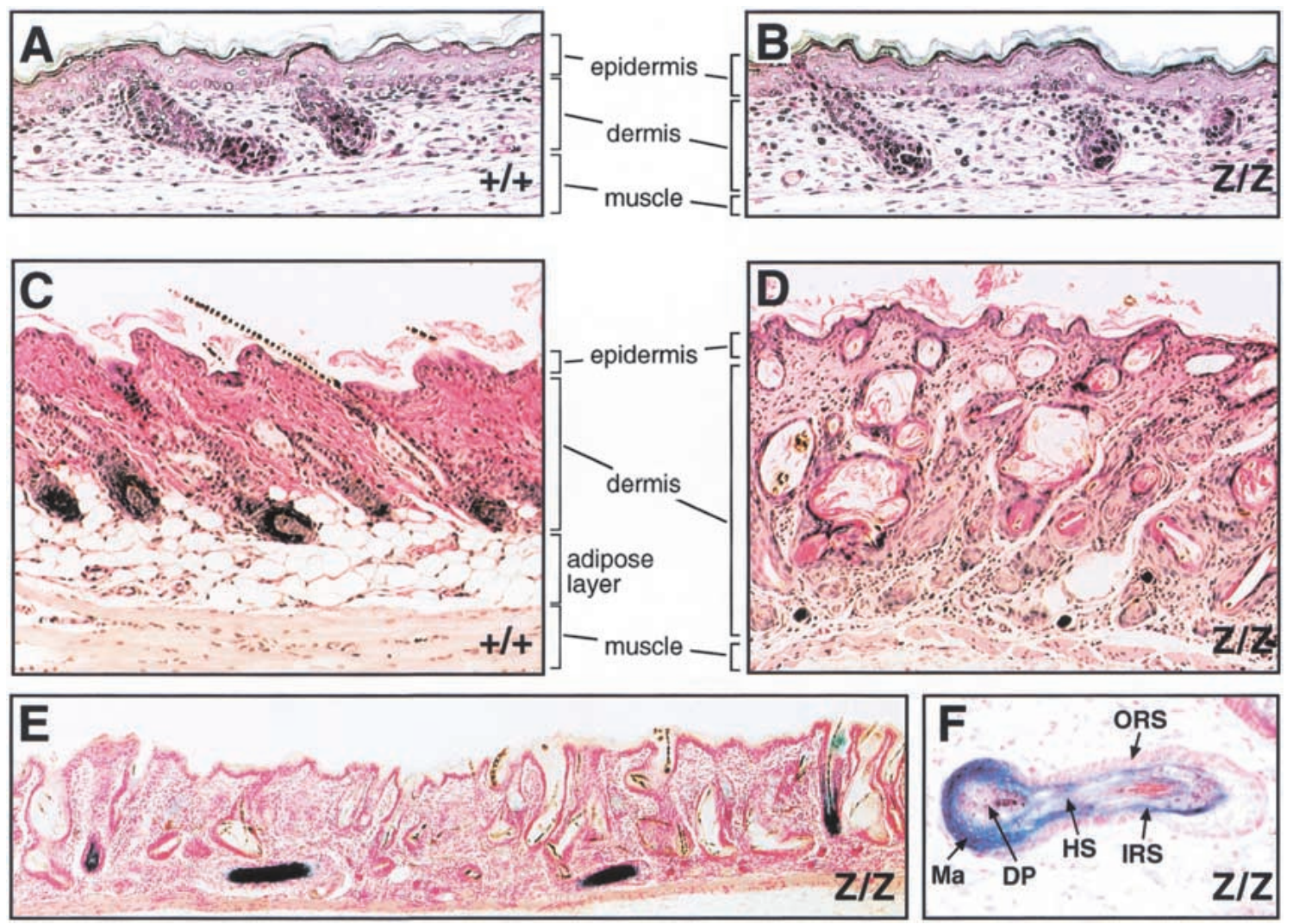

Figure 5. Disruption of hair follicle development in the skin of Cutl1 mutant mice. $(A-D)$ Histological analysis of the skin from wild-type and Cut11 ${ }^{Z / Z}$ mice at E18.5 $(A, B)$ and postnatal day $21(C, D)$, respectively. $(E) \beta$-Galactosidase staining of a skin section from a 20-day-old Cut11 ${ }^{Z / Z}$ mouse. $(F)$ Higher magnification of an X-gal-stained Cut11 ${ }^{Z / Z}$ hair follicle that grew parallel to the epidermal surface. Cut11 mutant survivors on the C57BL/6 $\times 129 /$ Sv background were analyzed. (DP) Dermal papilla; (HS) hair shaft; (IRS) inner root sheath; (Ma) matrix; (ORS) outer root sheath.

lor et al. 2000; Oshima et al. 2001). Immunohistochemical staining of a wild-type whisker follicle with an antiCDP antibody showed that Cutl1 is not expressed in the upper part of the ORS (Fig. 6A,B), but is activated in keratinocytes arriving in the ORS of the bulb (Fig. 6C). Cut11 expression is subsequently maintained in the IRS progenitor cells of the matrix, in the three layers of the differentiating IRS (cuticle, Huxley's and Henlé's layers), and in the companion cell layer (Fig. 6A,B). The Cutl1 gene is, however, down-regulated in progenitors of the hair shaft and is subsequently not expressed in the three cell lineages constituting the hair (Fig. 6A-D). Consistent with this expression pattern, the differentiation of IRS cells was impaired in Cut $11^{Z / Z}$ whisker follicles (Fig. $6 \mathrm{E}, \mathrm{F})$. The cell layers of the IRS were reduced, whereas the ORS was enlarged, possibly as a secondary consequence of the alterations in the IRS. The absence of CDP did not, however, interfere with cell proliferation in the matrix region, as evidenced by the presence of many mitotic cells in the bulb of Cut11 ${ }^{Z / Z}$ follicles (Fig. 6F).

To investigate the molecular basis of the Cutl1 mutant phenotype, we compared the expression of IRS-specific genes in wild-type and mutant whisker follicles. Interestingly, the Cutl1 ${ }^{\text {lacz }}$ gene itself was expressed, in addition to the IRS, also in the cortex of homozygous
CDP-deficient follicles in marked contrast to heterozygous CDP-expressing follicles (Fig. 7D). Moreover, the cytokeratin K6hf, which is specifically expressed in the companion cell layer of wild-type follicles (Winter et al. 1998), was detected throughout the IRS as well as in the cortex of Cutl1 ${ }^{\text {Z/Z }}$ follicles (Fig. 7E). Likewise, the IRSspecific cytokeratin K6irs and keratin-associated trichohyalin protein were misexpressed in the cortex of mutant hair follicles (Fig. 7A; data not shown). Therefore, these results indicate that the loss of CDP leads to deregulated expression of IRS-specific genes in the hair shaft.

However, the Cut $11^{z}$ mutation did not affect the regulation of genes that are expressed during differentiation of the hair-shaft lineages. Expression of the hair keratin Hacl-1 and the transcription factor Foxn1 (Whn) also remained restricted to the cortex in mutant hair follicles (Fig. 7B,C). Moreover, we did not observe any difference in gene expression of the hair keratin MHKA-1; the transcription factors Lef1, Msx2, and Hairless; the Notch1 receptor; and the secreted proteins Bmp2, Bmp4, and Wnt3a between wild-type and mutant follicles (data not shown). Importantly, however, the expression of the signaling molecule Sonic hedgehog (Shh) was deregulated in the absence of CDP. Whereas Shh is expressed in small 
Ellis et al.

Figure 6. Abnormal differentiation of the inner root sheath in Cut $11^{Z / Z}$ whisker follicles. (A) Expression of the CDP protein in the wild-type whisker follicle. A longitudinal section through the whisker follicle of a 5-day-old mouse was stained with the anti-CDP antibody C3HD and counterstained with hematoxylin. $(B, C)$ Higher magnification of the areas indicated in $A$. Brown staining identifies nuclear expression of CDP in the inner root sheath (IRS) including the companion cell layer (CCL). (D) Schematic diagram of hair follicle differentiation. Multipotent stem cells migrate from the bulge through the outer root sheath (ORS) to the hair bulb, where they become committed to the different cell lineages of the IRS and hair shaft (HS). Gray shading denotes CDP expression in the different cell layers. $(E, F)$ Histological sections of wild-type $(E)$ and Cut11 mutant $(F)$ whisker follicles at birth. The boxed areas are shown above at higher magnification. Mitotic cells are indicated by arrowheads. (Co) Cortex; (DP) dermal papilla; $(\mathrm{Cu})$ cuticle layer of the IRS; $(\mathrm{HCu})$ cuticle layer of the hair; $(\mathrm{He})$ Henlé's layer; $(\mathrm{Hu})$ Huxley's layer; (Ma) matrix; (Me) medulla.

A

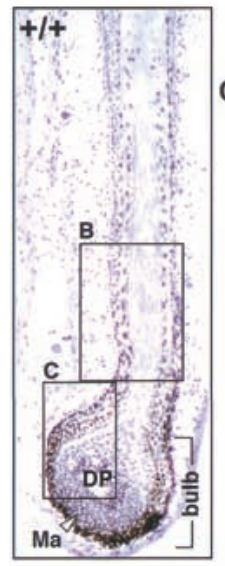

D

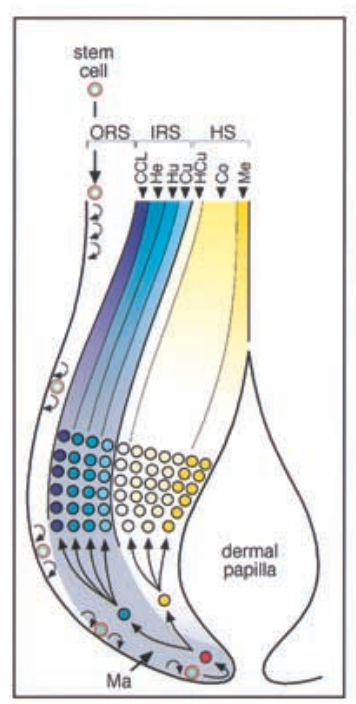

B

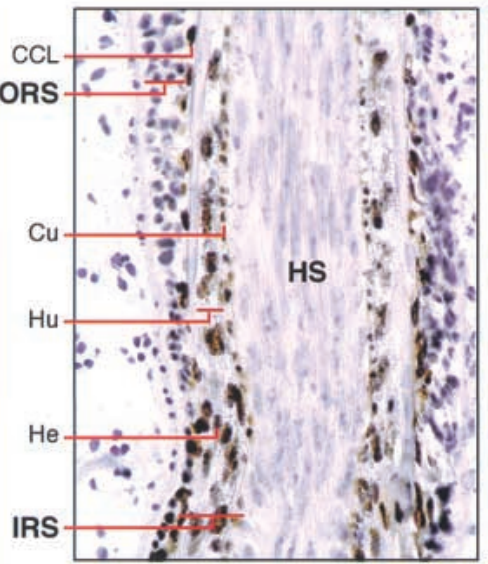

C

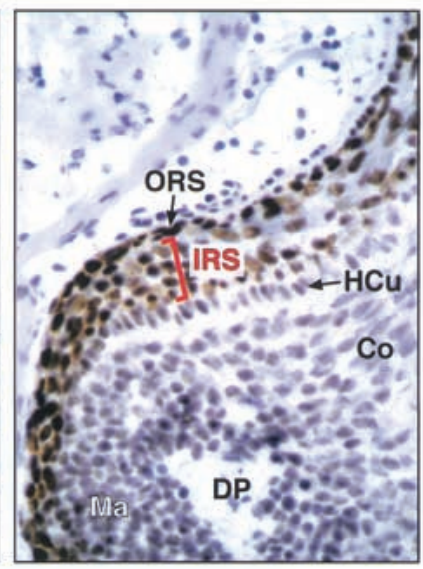

E
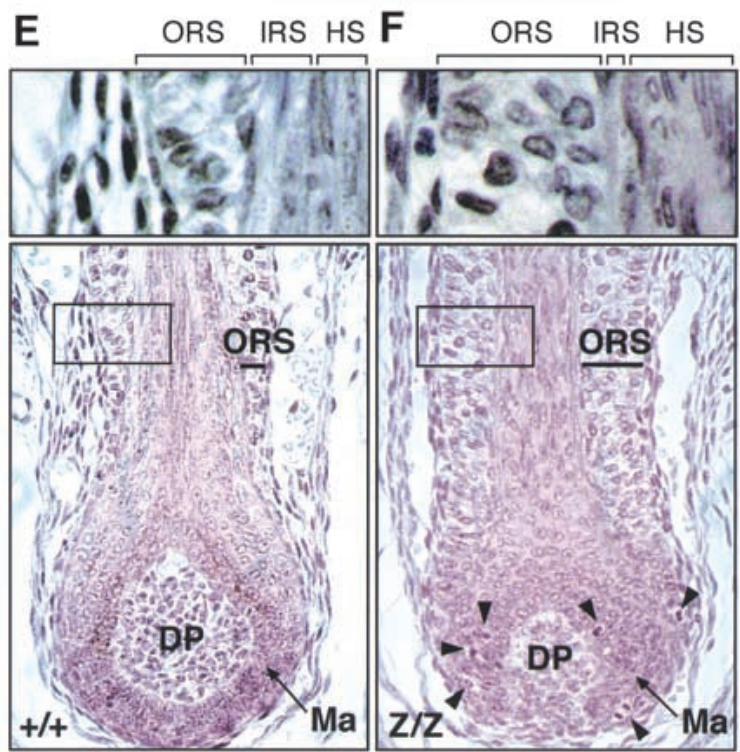

cell populations on either side of Auber's line within the matrix of wild-type whisker follicles (Gambardella et al. 2000), its expression was lost in the matrix and was instead relocated to the IRS in Cut11 mutant follicles (Fig. $7 \mathrm{~F})$. In conclusion, these data show that CDP is essential for proper differentiation of the IRS by controlling the correct spatial expression of Shh and IRS-specific genes. Hence, CDP is a key regulator of cell-lineage specification in hair follicle development.

\section{Discussion}

Many diverse functions have been assigned to the vertebrate transcription factor CDP based on the identification of a multitude of CDP target genes, although they have not been subjected to stringent genetic tests. A previous attempt to inactivate the mouse Cutl1 gene resulted in a hypomorphic allele, as alternative splicing skipped over the neomycin-resistance gene replacing exon 10 and thus gave rise to a CDP protein lacking Cut repeat 1 (Tufarelli et al. 1998). Homozygous Cutl1 ${ }^{\Delta C R 1}$ mutant mice were viable and developed a coat of slightly wavy hair, although this phenotype was lost with progressing age (Tufarelli et al. 1998). Here we describe a novel Cut11 mutation replacing C-terminal CDP sequences with an in-frame lac $Z$ gene. Mice homozygous for this mutation display a severe phenotype characterized by general growth retardation, delayed lung maturation, and impaired hair follicle development.

Expression analysis of the lacZ knock-in allele revealed Cutl1 expression in the epithelial compartments of many organs that depend on epithelial-mesenchymal interactions for their development. However, we failed to detect morphological alterations of these epithelial organs in Cut $11^{Z / Z}$ mice except for the lung and hair follicle. The absence of a mutant phenotype could be due to several reasons. First, Cutl1 may indeed not be essential for the differentiation of these organs in spite of its expression. This is, however, contrasted by the fact that null mutations of the Drosophila cut gene result in embryonic lethality caused by multiple developmental defects (Blochlinger et al. 1988). A more likely explanation 

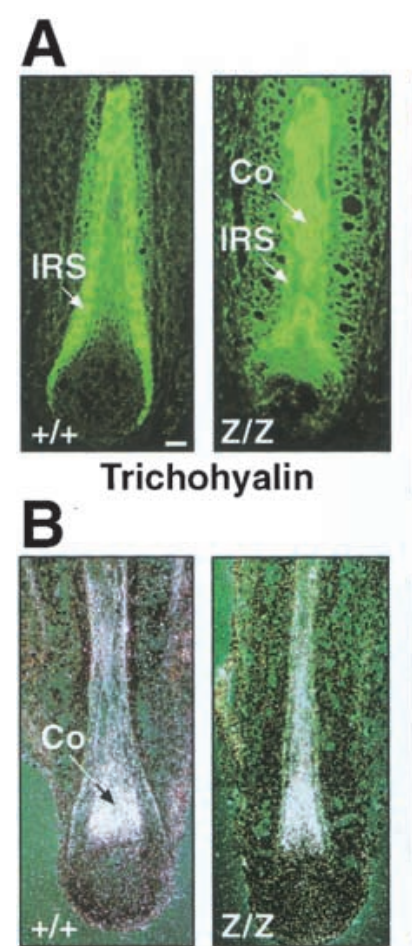

Hacl-1

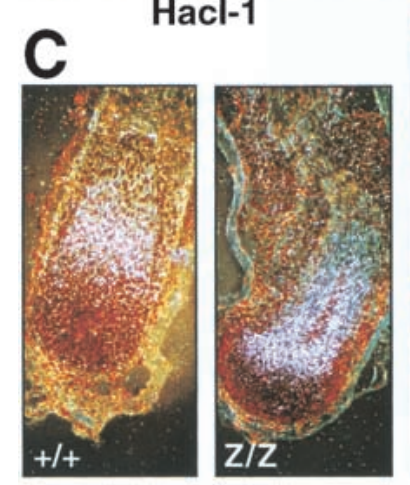

Foxn1
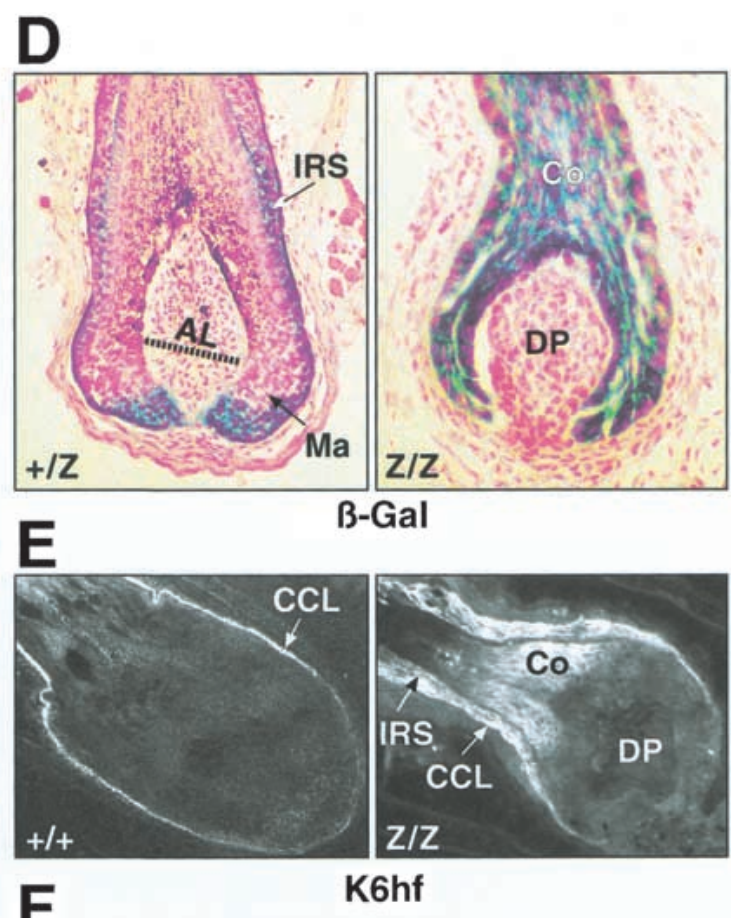

B-Gal

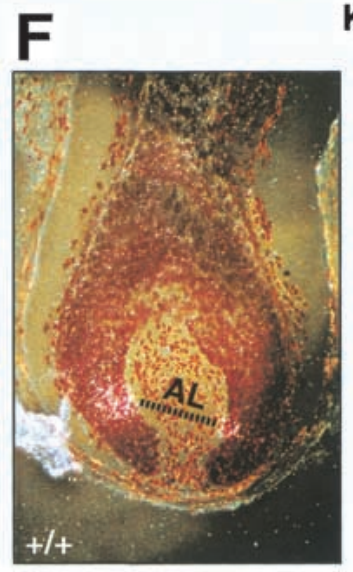

Shh
Figure 7. Deregulated expression of Shh and IRS-specific genes in Cut11 ${ }^{Z / Z}$ whisker follicles. Whisker follicles in the growth phase of the hair cycle were taken from adult wild-type and Cut11 mutant mice and analyzed for the expression of the indicated genes by $\beta$-galactosidase staining $(D)$, immunohistochemistry $(A, E)$, and in situ hybridization $(B, C, F)$. Hacl-1 $(B)$ and K6hf $(E)$ are cytokeratins, and trichohyalin $(A)$ is a keratin-associated protein. The transcription factor Foxn1 $(H)$ is also known as Whn, encoded by the nude gene. $\operatorname{Shh}(F)$ is expressed in the matrix of wildtype whisker follicles within small cell populations on either side of Auber's line (AL, dotted line), which characterizes the largest diameter of the dermal papilla (Gambardella et al. 2000). (Ma) matrix; (CCL) companion cell layer; (IRS) inner root sheath. is provided by the existence of two vertebrate Cutl genes, which may fulfill redundant functions in development. Although the mouse Cutl2 gene was reported to be exclusively expressed in the central and peripheral nervous systems (Quaggin et al. 1996), it remains a possibility that transcripts of this gene were not detected in other tissues because of the generally low expression of Cutl genes. In support of this, the chicken Cutl2 gene was recently shown to be expressed in the epithelial structures of the developing kidney (Tavares et al. 2000). Analogous expression of the mouse Cutl2 gene could therefore compensate for the loss of CDP function in kidney development of Cut11 mutant mice.

Finally, the $\mathrm{Cutl}^{Z}$ mutation could be a hypomorphic allele in view of the fact that the $\mathrm{N}$-terminal 1150 amino acids of CDP are still present in the CDP-lacZ fusion protein. However, all available evidence suggests that the $\mathrm{Cutl1}^{Z}$ mutation corresponds to a null allele, as the CDP-lacZ protein is retained in the cytoplasm and fails to function as a repressor or dominant-negative protein. Interestingly, the postmeiotic spermatids in the testis abundantly express a short CDP isoform that consists entirely of the C-terminal sequences (Vanden Heuvel et al. 1996) deleted in the Cutl1 ${ }^{Z}$ allele. In the absence of this isoform, the Cut $11^{Z / Z}$ males were still fertile, showing that CDP is not essential for spermiogenesis. Likewise, limb development was entirely normal in Cut $11^{Z / Z}$ mice (Fig. 2B), although misexpression experiments have recently implicated the chicken Cutl1 gene in the control of limb morphogenesis (Tavares et al. 2000).

\section{Essential role of Cutl1 in growth control and lung maturation}

One prevailing hypothesis about the CDP function in hematopoiesis states that Cutl1 expression at early stages represses lineage-specific genes, which are activated only during the CDP-negative phase of terminal 
differentiation (Skalnik et al. 1991; Lievens et al. 1995; Wang et al. 1999). However, our expression analysis in hematopoietic cells failed to support this hypothesis, as expression of the Cutl1 lacZ gene was not inversely correlated with terminal differentiation in the B-lymphoid and myeloid lineages (data not shown). Moreover, the

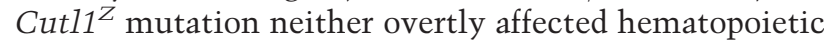
cell differentiation nor altered expression of the putative CDP target genes $C D 8 \alpha, T C R \beta$, and $\operatorname{Ig} H$ (data not shown).

The second prevailing hypothesis implicates CDP in the control of cell proliferation, as putative CDP target genes code for the cell-cycle-regulated Cdk inhibitor p $21^{\text {WAF1/CIP1 }}$, c-Myc, thymidine kinase, and histones (for review, see Nepveu 2001). Further support was provided by the cell-cycle-dependent regulation of the DNA-binding activity and complex formation of CDP with cyclin $\mathrm{A}, \mathrm{Cdk} 2$, and Rb-related proteins in cultured fibroblasts (van Wijnen et al. 1996; Coqueret et al. 1998). Contrary to expectation, primary fibroblasts established from Cut11 ${ }^{Z / Z}$ embryos proliferated as well as wild-type control cells (data not shown), indicating that CDP is not a critical regulator of cell-cycle progression in fibroblasts. However, we cannot exclude that a proliferative function of CDP may be responsible for the growth-retardation phenotype of Cut $11^{Z / Z}$ mice.

Lung development is initiated by the outpouching of foregut endoderm into the splanchnic mesenchyme and is subsequently guided by reciprocal epithelial-mesenchymal interactions that control the proliferation, branching, and differentiation of the lung epithelium (Burri 1999). Cutl1 is expressed in lung epithelial cells as early as E12.5, but is dispensable for branching morphogenesis in Cutl1 ${ }^{Z / Z}$ embryos. However, during the saccular stage of lung development CDP is essential for differentiation of the cuboidal epithelial precursor cells into functional type I and II pneumocytes. Inbred $\mathrm{Cutl1}^{Z / Z}$ mice are born with thick, nonfunctional lung epithelia and die shortly after birth from respiratory failure. A similar immature lung phenotype was observed previously in mice lacking the epidermal growth factor receptor (Sibilia and Wagner 1995), glucocorticoid receptor (Cole et al. 1995), or TGF- 33 (Kaartinen et al. 1995). However, none of these genes is under the control of $\mathrm{CDP}$, as they were normally expressed in the lung epithelia of newborn Cutl1 ${ }^{Z / Z}$ mice (data not shown). Interestingly, the Cutl1 ${ }^{Z}$ mutation on the outbred OF1 background caused a less severe delay in pneumocyte differentiation and was therefore compatible with survival beyond birth. Hence, genetic modifier loci influence the severity of the lung phenotype in different mouse strains by altering the dependency of pneumocyte differentiation on CDP function.

\section{Cutl1-dependent cell fate specification in hair follicle development}

In contrast to the lung, the Cut $11^{Z}$ mutation disrupts hair follicle development in a strain background-independent manner. The initial phase of hair follicle devel- opment, which relies on inductive interactions between selected epidermal keratinocytes and underlying dermal fibroblasts, proceeds normally in Cut $11^{Z / Z}$ embryos. However, the later differentiation of stem cells into distinct lineages of the hair follicle is affected in the absence of CDP. During the growth phase of hair follicle development, the stem cells migrate from the bulge through the basal layer of the outer root sheath (ORS) to the matrix region of the bulb, where they proliferate under the influence of signals from the dermal papilla. These proliferating progenitors subsequently undergo lineage commitment, withdraw from the cell cycle, and enter one of seven vertical differentiation pathways, giving rise to the concentric layers of the IRS and hair shaft (Fig. 6D; Taylor et al. 2000; Oshima et al. 2001). The Cutl1 expression pattern in the hair follicle is unique, as its transcription is initiated in stem cells reaching the bulb and is then maintained in the proliferating IRS progenitor cells, in the differentiating cells of the cuticle, Huxley's and Henlé's layers of the IRS, and in the adjacent companion cell layer. Although the companion cells are thought to constitute the innermost layer of the ORS, they form only few connections with other cells in the ORS (Rothnagel and Roop 1995). In contrast, however, the companion cells are in intimate contact with cells of Henlé's layer through desmosomes and gap junctions and therefore may form a slippage plane to allow the growing hair fiber to move along the ORS (Rothnagel and Roop 1995). Moreover, the elongated and vertically oriented companion cells are also morphologically and biochemically distinct from the cuboidal ORS cells, which has led to the hypothesis that the companion cells constitute an independent histological compartment of the hair follicle (Rothnagel and Roop 1995; Winter et al. 1998). The coexpression of Cutl1 in the IRS and companion cells now strongly argues that the companion cells constitute the fourth and outermost layer of the IRS.

The IRS-specific expression of Cutl1 is consistent with the observed reduction of IRS cell layers in the Cut11 ${ }^{Z / Z}$ hair follicle, which suggests a cell-autonomous role of CDP in IRS cell differentiation. This defect in IRS formation is likely to be a primary cause for the dramatic disruption of hair follicle morphogenesis in Cut $11^{Z / Z}$ mice. The IRS normally envelops the developing hair fiber and migrates upward together with it, until it cornifies upon terminal differentiation and is separated from the hair by extrusion into the infundibulum at the upper follicle end (Philpott and Paus 1998). Aberrant IRS differentiation in the Cut $11^{Z / Z}$ hair follicle interferes with this normal function of the IRS and thus fails to support proper growth of the hair fiber, leading to multiple hair abnormalities.

At the molecular level, the loss of CDP function leads to the ectopic expression of IRS-specific genes (Cutl1, K6hf, K6irs, and trichohyalin) in the cortex of the hair shaft. The continued expression of the Cutl1 1 lacZ gene in hair shaft cells of homozygous mutants was surprising, as CDP cannot be directly involved in the repression of its own gene for the following reasons. First, CDP does 
not repress its own transcription in the IRS layers of wild-type hair follicles. Second, CDP is normally not expressed in hair shaft cells and therefore is not available to repress IRS-specific genes in this compartment. It is therefore more likely that CDP is involved in regulating the expression of an non-cell-autonomous signal that instructs progenitor cells of the hair shaft lineages to inactivate the Cutl1 gene together with the IRS-specific gene expression program. Indeed, Shh expression is lost in the matrix cells of Cutl1 mutant whisker follicles, where it is normally transcribed in a ring-like fashion along Auber's line (Gambardella et al. 2000). However, the expression domain of Shh does not overlap with that of Cut11 in the matrix region (Fig. $7 \mathrm{D}, \mathrm{F})$, suggesting that CDP is indirectly involved in the activation of Shh in matrix cells of wild-type mice. In contrast, CDP may directly repress Shh transcription in IRS cells, whereas Shh becomes derepressed in Cut $11^{Z / Z}$ whisker follicles. To what degree ectopic expression of Shh contributes to the Cut11 mutant phenotype is unclear at present based on published loss- and gain-of-function data. Disruption of the Shh gene or treatment with neutralizing anti-hedgehog antibodies revealed an essential role of Shh in controlling the down-growth and morphogenesis of the hair follicle (St-Jacques et al. 1998; Chiang et al. 1999; Wang et al. 2000). On the other hand, transient ectopic expression of Shh in the skin induced resting hair follicles to enter the growth phase of the next hair cycle (Sato et al. 1999). Moreover, deregulated Shh expression in the matrix region was previously associated with misangling of hair follicles (Gat et al. 1998), which is also observed in the Cutl1 mutant skin. Ectopic Shh signaling emanating from IRS cells of the Cutl1 $1^{Z / Z}$ hair follicle could also be responsible for the observed thickening of the ORS, where Cutl1 is not expressed. In summary, our data show that CDP uses cell-intrinsic and non-cell-autonomous mechanisms to control cell lineage specification during hair follicle morphogenesis. This function of CDP resembles the role of Drosophila Cut in specifying cell fates during peripheral nervous system development (Blochlinger et al. 1988, 1991).

\section{Materials and methods}

\section{Generation of Cutl1 mutant mice}

The Cut11 targeting vector was assembled in plasmid pGNA containing a polylinker with appropriate restriction sites. A 1.8kb BsaI fragment (short homology arm) of the Cutl1 gene was linked in the Cut repeat 3 exon 22 to the lacZ gene of pGNA via an adaptor oligonucleotide resulting in the following amino acid insertion (underlined): LFGETLEKIFRNSAKKKRKVEDPKDF PSELLSFLSPSLALAVVL. A 3.8-kb SphI-BamHI fragment (long homology arm) encompassing Cut11 intron 23 was then inserted together with a $1.9-\mathrm{kb} \mathrm{XbaI}-\mathrm{NotI}$ fragment containing the $t \mathrm{k}$ gene. NotI-linearized DNA $(15 \mu \mathrm{g})$ of the pGNA-Cutl1 targeting vector was electroporated into E14.1 ES cells $\left(1 \times 10^{7}\right)$ followed by selection with $150 \mu \mathrm{g} / \mathrm{mL}$ of bioactive G418. Individual clones were screened by PCR for homologous recombination, and PCR-positive clones were verified by Southern blot analysis
(Fig. 1A). Two of four correctly targeted ES cell clones gave rise to germ-line transmission after injection into C57BL/6 blastocysts. The Cut $11^{Z}$ allele was maintained on the C57BL/6 $\times 129$ / Sv background as well as back-crossed into the $\mathrm{C} 3 \mathrm{H} / \mathrm{He}$ and albino OF1 strains (Iffa Credo, France). Cutl1 mutant mice were genotyped by PCR with the following primers: (1) $5^{\prime}$-TGCT CATCCACCTGCCTCAATGTC-3', (2) 5'-ATCCATCAGCT TCTCCACATTGTT-3', and (3) 5' -TCCTGTAGCCAGCTTTC ATCAACA-3'. The wild-type and ${ }^{\prime}{ }^{\prime} u t 11^{Z}$ alleles gave rise to PCR products of $615 \mathrm{bp}$ (primers 1/2) and $962 \mathrm{bp}$ (primers 1/3), respectively.

\section{Histological analysis and $\beta$-galactosidase staining}

Embryos or dissected organs were fixed in $4 \%$ formaldehyde/ PBS, and 7- $\mu \mathrm{m}$ paraffin-embedded sections were stained with eosin and hematoxylin. For $\beta$-galactosidase staining, the samples were fixed for $30 \mathrm{~min}$ at room temperature in buffer $\mathrm{X}$ $\left(0.2 \%\right.$ gluteraldehyde, $0.1 \mathrm{M} \mathrm{NaH}_{2} \mathrm{PO}_{4}$ at $\mathrm{pH} 7.2,5 \mathrm{mM}$ EGTA, $\left.2 \mathrm{mM} \mathrm{MgCl}_{2}\right)$, washed in buffer $\mathrm{W}\left(0.1 \mathrm{M} \mathrm{NaH}_{2} \mathrm{PO}_{4}\right.$ at $\mathrm{pH} 7.2$, $2 \mathrm{mM} \mathrm{MgCl}_{2}, 0.01 \%$ deoxycholate, $\left.0.03 \% \mathrm{NP} 40\right)$, and sequentially incubated in solutions of $10 \%-30 \%$ sucrose. The samples were embedded in Tissue-Tek O.C.T. medium (Sakura) and quick-frozen in liquid nitrogen. Cyrosections were postfixed for $10 \mathrm{~min}$ in buffer $\mathrm{X}$, stained with $0.67 \mathrm{mg} / \mathrm{mL}$ X-gal (5-bromo-4chloro-3-indolyl- $\beta$-D-galactoside) in buffer $\mathrm{W}$, and counterstained with $0.1 \%$ Nuclear Fast Red in 5\% aluminum sulfate.

\section{Anti-CDP antibody}

A 432-bp PCR fragment was amplified from pRK5-mCDP with primers 5'-gegggatccCAGGGTTCTGTCTCCGACCTC-3' and 5'-gcgggatccttaGCGGCGAATCCGAGACCTGTAATT-3' and inserted into the BamHI site of the bacterial expression vector pETH-2a (Adams et al. 1992). The recombinant CDP polypeptide (starting with QGSV in Cut repeat 3 and ending with PIRR in the homeodomain) was expressed, purified, and injected into rabbits to generate the polyclonal anti-CDP serum $\mathrm{C} 3 \mathrm{HD}$, as described (Adams et al. 1992).

\section{Immunohistochemistry}

Cryosections of whisker follicles were stained with the antitrichohyalin antibody AE15 (Wang et al. 2000) and anti-K6hf antibody Bax-1 (Winter et al. 1998), as described. For CDP staining, cryosections were incubated overnight at $4^{\circ} \mathrm{C}$ with the affinity-purified C3HD antibody $(0.3 \mu \mathrm{g} / \mathrm{mL})$, which was detected with biotinylated goat anti-rabbit IgG followed by DAB staining with the Vectastain ABC kit (Vector Labs).

Primary fibroblasts, established from $\mathrm{Cutl}^{+/ Z}$ embryos at E13.5 by the 3 T3 protocol, were fixed in $1 \%$ formaldehyde/PBS at $25^{\circ} \mathrm{C}$ for $20 \mathrm{~min}$, blocked in $3 \% \mathrm{BSA} / \mathrm{PBS}$ for $30 \mathrm{~min}$, and incubated overnight at $4^{\circ} \mathrm{C}$ with the affinity-purified C3HD antibody $(0.3 \mu \mathrm{g} / \mathrm{mL})$ and a biotinylated anti- $\beta$-Gal antibody (Sigma). Polyclonal and biotinylated antibodies were detected by incubation with a Cy5-labeled goat anti-rabbit antibody (Jackson Laboratories) and Alexa488-conjugated avidin (Molecular Probes), respectively.

\section{EM and histological analyses of the lung}

The trachea of anesthetized mice were cannulated, and the lungs were fixed by intratracheal instillation of a $2.5 \% \mathrm{KH}_{2} \mathrm{PO}_{4}$ buffered glutaraldehyde solution ( $\mathrm{pH} 7.4,360 \mathrm{mOsm})$ after provoking a pneumothorax by puncturing the diaphragm. After dissection, the lungs were fixed in the same solution for a further 
$24 \mathrm{~h}$ at $4^{\circ} \mathrm{C}$. Paraffin-embedded $4-\mu \mathrm{m}$ sections of the left lobe were stained with fuchsin for light microscopic investigation. For EM analysis, the right lobe was postfixed in $1 \%$ osmium tetroxide, contrasted in $0.5 \%$ uranyl acetate, and embedded in Epon 812. Ultrathin sections $(80 \mathrm{~nm})$ on 22 -mesh grids were stained with uranyl acetate and lead citrate, followed by examination in a Philips EM 300.

\section{In situ hybridization}

Whisker follicles of albino OF1 mice were analyzed by in situ hybridization with gene-specific ${ }^{33} \mathrm{P}$-labeled antisense oligonucleotides (45 nt) as described (Wang et al. 2000). The oligonucleotide sequences are available on request (busslinger@ nt.imp.univie.ac.at).

\section{Hormone measurements}

Growth hormone $(\mathrm{GH})$ and thyroid-stimulating hormone (TSH) were measured in the sera of 2-week-old OF1 mice by radioimmunoassay at the Institute of National Hormone and Pituitary Program (Torrance, CA).

\section{Cell transfection assay}

The full-length CDP cDNA insert of pRK5-mCDP was isolated as a $4.9-\mathrm{kb}$ XbaI-ClaI fragment by RT-PCR from mouse 70Z/3 pre-B cells. pRK5-mCDP-lacZ was generated by inserting a 3087-bp XbaI-DraIII fragment (N-terminal CDP sequences) of pRK5-mCDP, a 378-bp DraIII-XhoI PCR fragment (CDP-lacZ linker), and a 3552-bp XhoI-BamHI fragment (C-terminal lacZ sequences) of pGNA-Cutl1 into the expression vector pRK5. The DraIII-XhoI linker fragment was obtained by RT-PCR from lung RNA of Cut $11^{Z / Z}$ embryos. The promoter of SP1- $\gamma$-TATAGH (Lievens et al. 1995) was PCR-amplified and inserted into pGL3-Basic to generate SP1- $\gamma$-TATA-luc. These DNAs were transiently transfected into NIH 3T3 cells by the LipofectAMINE PLUS Reagent (GIBCO BRL).

\section{Accession number}

The mouse CDP cDNA sequence of pRK5-mCDP was submitted to DBBJ/EMBL/GenBank with accession no. AY037807.

\section{Acknowledgments}

We thank E. Neufeld for the SP1- $\gamma$-TATA-GH construct, A.F. Parlow for hormone measurements, A. Nepveu for the N(-861) antibody, L. Langbein for the K6hf and K6irs antibodies, C. Theußl for blastocyst injection, and G. Schaffner for DNA sequencing. This research was supported by Boehringer Ingelheim, the Austrian Industrial Research Promotion Fund, ARC and INSERM (grant CRI 9602 to Y.B.), and the French Ministry of Education, Research and Technology (student fellowship for L.G.).

The publication costs of this article were defrayed in part by payment of page charges. This article must therefore be hereby marked "advertisement" in accordance with 18 USC section 1734 solely to indicate this fact.

\section{References}

Adams, B., Dörfler, P., Aguzzi, A., Kozmik, Z., Urbánek, P., Maurer-Fogy, I., and Busslinger, M. 1992. Pax-5 encodes the transcription factor BSAP and is expressed in B lymphocytes, the developing CNS, and adult testis. Genes \& Dev. 6: 15891607.

Banan, M., Rojas, I.C., Lee, W.-H., King, H.L., Harriss, J.V., Kobayashi, R., Webb C.F., and Gottlieb, P.D. 1997. Interaction of the nuclear matrix-associated region (MAR)-binding proteins, SATB1 and CDP/Cux, with a MAR element (L2a) in an upstream regulatory region of the mouse CD8a gene. J. Biol. Chem. 272: 18440-18452.

Barberis, A., Superti-Furga, G., and Busslinger, M. 1987. Mutually exclusive interaction of the CCAAT-binding factor and of a displacement protein with overlapping sequences of a histone gene promoter. Cell 50: 347-359.

Blochlinger, K., Bodmer, R., Jack, J., Jan, L.Y., and Jan, Y.N. 1988. Primary structure and expression of a product from cut, a locus involved in specifying sensory organ identity in Drosophila. Nature 333: 629-635.

Blochlinger, K., Jan, L.Y., and Jan, Y.N. 1991. Transformation of sensory organ identity by ectopic expression of Cut in Drosophila. Genes \& Dev. 5: 1124-1135.

Burri, P.H. 1999. Lung development and pulmonary angiogenesis. In Lung development (eds. C. Gaultier et al.), pp. 122151. Oxford University Press, New York, NY.

Chattopadhyay, S., Whitehurst, C.E., and Chen, J. 1998. A nuclear matrix attachment region upstream of the $T$ cell receptor $\beta$ gene enhancer binds Cux/CDP and SATB1 and modulates enhancer-dependent reporter gene expression but not endogenous gene expression. J. Biol. Chem. 273: 2983829846.

Chiang, C., Swan, R.Z., Grachtchouk, M., Bolinger, M., Litingtung, Y., Roberston, E.K., Cooper, M.K., Gaffield, W., Westphal, H., Beachy, P.A., et al. 1999. Essential role of Sonic hedgehog during hair follicle morphogenesis. Dev. Biol. 205: 1-9.

Cole, T.J., Blendy, J.A., Monaghan, A.P., Krieglstein, K., Schmid, W., Aguzzi, A., Fantuzzi, G., Hummler, E., Unsicker, K., and Schütz, G. 1995. Targeted disruption of the glucocorticoid receptor gene blocks adrenergic chromaffin cell development and severely retards lung maturation. Genes \& Dev. 9: 1608-1621.

Coqueret, O., Bérubé, G., and Nepveu, A. 1998. The mammalian Cut homeodomain protein functions as a cell-cycle-dependent transcriptional repressor which downmodulates p21WAF1/CIP1/SDI1 in S phase. EMBO J. 17: 4680-4694.

Gambardella, L., Schneider-Maunoury, S., Voiculescu, O., Charnay, P., and Barrandon, Y. 2000. Pattern of expression of the transcription factor Krox-20 in mouse hair follicle. Mech. Dev. 96: 215-218.

Gat, U., DasGupta, R., Degenstein, L., and Fuchs, E. 1998. De novo hair follicle morphogenesis and hair tumors in mice expressing a truncated $\beta$-catenin in skin. Cell 95: 605-614.

Jackson, S.M. and Blochlinger, K. 1997. cut interacts with Notch and Protein kinase A to regulate egg chamber formation and to maintain germline cyst integrity during Drosophila oogenesis. Development 124: 3663-3672.

Kaartinen, V., Voncken, J.W., Shuler, C., Warburton, D., Bu, D. Heisterkamp, N., and Groffen, J. 1995. Abnormal lung development and cleft palate in mice lacking TGF- $\beta 3$ indicates defects of epithelial-mesenchymal interaction. Nat. Genet. 11: 415-421.

Li, S., Moy, L., Pittman, N., Shue, G., Aufiero, B., Neufeld, E.J., LeLeiko, N.S., and Walsh, M.J. 1999. Transcriptional repression of the cystic fibrosis transmembrane conductance regulator gene, mediated by CCAAT displacement protein/cut homolog, is associated with histone deacetylation. I. Biol. Chem. 274: 7803-7815.

Lievens, P.M.J., Donady, J.J., Tufarelli, C., and Neufeld, E.J. 
1995. Repressor activity of CCAAT displacement protein in HL-60 myeloid leukemia cells. J. Biol. Chem. 270: 1274512750.

Lievens, P.M.J., Tufarelli, C., Donady, J.J., Stagg, A., and Neufeld, E.J. 1997. CASP, a novel, highly conserved alternativesplicing product of the $\mathrm{CDP} /$ cut/cux gene, lacks cut-repeat and homeo DNA-binding domains, and interacts with fulllength CDP in vitro. Gene 197: 73-81.

Ludlow, C., Choy, R., and Blochlinger, K. 1996. Functional analysis of Drosophila and mammalian cut proteins in files. Dev. Biol. 178: 149-159.

Mailly, F., Bérubé, G., Harada, R., Mao, P.-L., Phillips, S., and Nepveu, A. 1996. The human Cut homeodomain protein can repress gene expression by two distinct mechanisms: Active repression and competition for binding site occupancy. Mol. Cell. Biol. 16: 5346-5357.

Micchelli, C.A., Rulifson, E.J., and Blair, S.S. 1997. The function and regulation of cut expression on the wing margin of Drosophila: Notch, Wingless and a dominant negative role for Delta and Serrate. Development 124: 1485-1495.

Moon, N.S., Berube, G., and Nepveu, A. 2000. CCAAT displacement activity involves Cut repeats 1 and 2 and not the Cut homeodomain. J. Biol. Chem. 275: 31325-31334.

Nepveu, A. 2001. Role of the multifunctional CDP/Cut/Cux homeodomain transcription factor in regulating differentiation, cell growth and development. Gene 270: 1-15.

Neufeld, E.J., Skalnik, D.G., Lievens, P.M.-J., and Orkin, S.H. 1992. Human CCAAT displacement protein is homologous to the Drosophila homeoprotein, cut. Nat. Genet. 1: 50-55.

Oshima, H., Rochat, A., Kedzia, C., Kobayashi, K., and Barrandon, Y. 2001. Morphogenesis and renewal of hair follicles from adult multipotent stem cells. Cell 104: 233-245.

Philpott, M. and Paus, R. 1998. Principles of hair follicle morphogenesis. In Molecular basis of epithelial appendage morphogenesis (ed. C.-M. Chuong), pp. 75-110. R.G. Landes, Austin, TX.

Quaggin, S.E., Vanden Heuvel, G.B., Golden, K., Bodmer, R., and Igarashi, P. 1996. Primary structure, neural-specific expression, and chromosomal localization of Cux-2, a second murine homeobox gene related to Drosophila cut. J. Biol. Chem. 271: 22624-22634.

Rothnagel, J.A. and Roop, D.R. 1995. Hair follicle companion layer: Reacquainting an old friend. I. Invest. Dermatol. 104: 42S-43S.

Sato, N., Leopold, P.L., and Crystal, R.G. 1999. Induction of the hair growth phase in postnatal mice by localized transient expression of Sonic hedgehog. I. Invest. Dermatol. 104: 855864.

Sibilia, M. and Wagner, E.F. 1995. Strain-dependent epithelial defects in mice lacking the EGF receptor. Science 269: 234 238.

Skalnik, D.G., Strauss, E.C., and Orkin, S.H. 1991. CCAAT displacement protein as a repressor of the myelomonocyticspecific gp91-phox gene promoter. J. Biol. Chem. 266: $16736-16744$.

St-Jacques, B., Dassule, H.R., Karavanova, I., Botchkarev, V.A., Li, J., Danielian, P.S., McMahon, J.A., Lewis, P.M., Paus, R., and McMahon, A.P. 1998. Sonic hedgehog signaling is essential for hair development. Curr. Biol. 8: 1058-1068.

Superti-Furga, G., Barberis, A., Schaffner, G., and Busslinger, M. 1988. The -117 mutation in Greek HPFH affects the binding of three nuclear factors to the CCAAT region of the $\gamma$-globin gene. EMBO J. 7: 3099-3107.

Tavares, A.T., Tsukui, T., and Izpisúa Belmonte, J.C. 2000. Evidence that members of the Cut/Cux/CDP family may be involved in AER positioning and polarizing activity during chick limb development. Development 127: 5133-5144.

Taylor, G., Lehrer, M.S., Jensen, P.J., Sun, T.-T., and Lavker, R.M. 2000. Involvement of follicular stem cells in forming not only the follicle but also the epidermis. Cell 102: 451461.

Tufarelli, C., Fujiwara, Y., Zappulla, D.C., and Neufeld, E.J. 1998. Hair defects and pup loss in mice with targeted deletion of the first cut repeat domain of the Cux/CDP homeoprotein gene. Dev. Biol. 200: 69-81.

Vanden Heuvel, G.B., Quaggin, S.E., and Igarashi, P. 1996. A unique variant of a homeobox gene related to Drosophila cut is expressed in mouse testis. Biol. Reprod. 55: 731-739.

van Wijnen, A.J., van Gurp, M.F., de Ridder, M.C., Tufarelli, C., Last, T.J., Birnbaum, M., Vaughan, P.S., Giordano, A., Krek, W., Neufeld, E.J., et al. 1996. CDP/cut is the DNA-binding subunit of histone gene transcription factor HiNF-D: A mechanism for gene regulation at the $G_{1} / S$ phase cell cycle transition point independent of transcription factor E2F. Proc. Nat1. Acad. Sci. 93: 11516-11521.

Wang, Z., Goldstein, A., Zong, R.T., Lin, D., Neufeld, E.J., Scheuermann, R.H., and Tucker, P.W. 1999. Cux/CDP homeoprotein is a component of NF- $\mu \mathrm{NR}$ and represses the immunoglobulin heavy chain intronic enhancer by antagonizing the bright transcription activator. Mol. Cell. Biol. 19: 284-295.

Wang, L.C., Liu, Z.-Y., Gambardella, L., Delacour, A., Shapiro, R., Yang, J., Sizing, I., Rayhorn, P., Garber, E.A., Benjamin, C.D., et al. 2000. Conditional disruption of hedgehog signaling pathway defines its critical role in hair development and regeneration. J. Invest. Dermatol. 114: 901-908.

Whiting, D.A. 1994. Hair shaft defects. In Disorders of hair growth: Diagnosis and treatment (ed. E.A. Olsen), pp. 91137. McGraw-Hill, New York, NY.

Winter, H., Langbein, L., Praetzel, S., Jacobs, M., Rogers, M.A., Leight, I.M., Tidman, N., and Schweizer, J. 1998. A novel human type II cytokeratin, K6hf, specifically expressed in the companion layer of the hair follicle. J. Invest. Dermatol. 111: 955-962.

Zeng, W.R., Soucie, E., Moon, N.S., Martin-Soudant, N., Bérubé, G., Leduy, L., and Nepveu, A. 2000. Exon/intron structure and alternative transcripts of the CUTL1 gene. Gene 241: 75-85. 


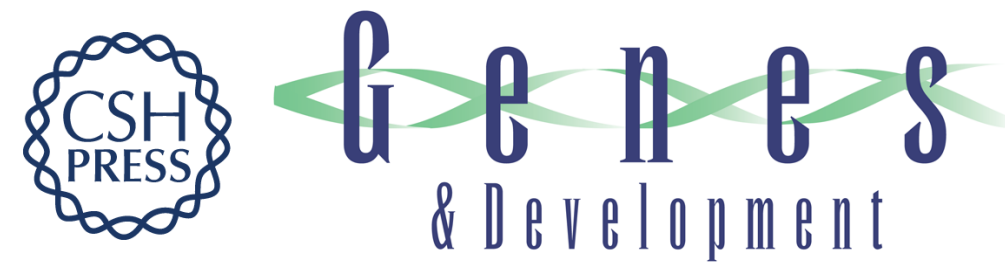

\section{The transcriptional repressor CDP (Cutl1) is essential for epithelial cell differentiation of the lung and the hair follicle}

Tammy Ellis, Laure Gambardella, Markus Horcher, et al.

Genes Dev. 2001, 15:

Access the most recent version at doi:10.1101/gad.200101

References

This article cites 39 articles, 18 of which can be accessed free at:

http://genesdev.cshlp.org/content/15/17/2307.full.html\#ref-list-1

License

Email Alerting

Receive free email alerts when new articles cite this article - sign up in the box at the top

Service right corner of the article or click here.

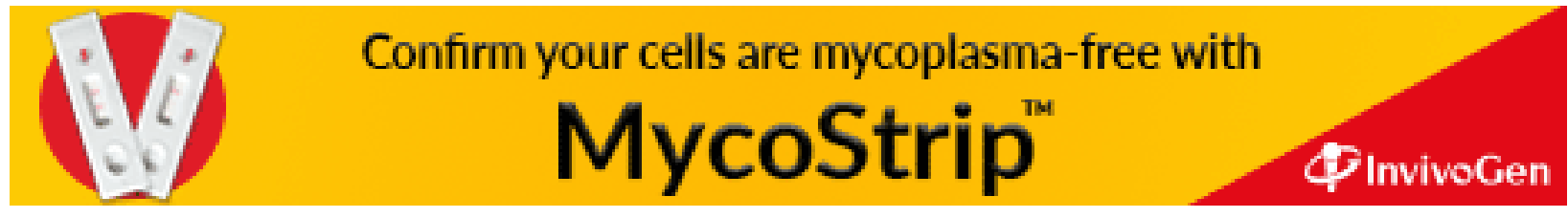

